\title{
Perencanaan Strategis Sistem Informasi dengan Metode Ward and Peppard Pada Perusahaan Ekspedisi (Studi kasus: Tiki Cabang Kota Salatiga)
}

\author{
Eka Ananta Supriyantoํ, Augie David Manuputty ${ }^{2}$
}

\begin{abstract}
Sistem Informasi, Fakultas Teknologi Informasi, Universitas Kristen Satya Wacana, Indonesia Email:1f682017057@student.uksw.edu,2augie.manuputty@uksw.edu
\end{abstract}

\begin{abstract}
Citra Van Titipan Kilat (TIKI) is a company engaged in the delivery of goods. Due to the growing development of IS/IT, then the increased competition with the emergence of new shipping service companies requires TIKI to be able to compete by improving service quality and performance. So this research was carried out with the aim of aligning IT/IS with business processes that were running in accordance with the vision and mission that had been set. In this study the data were obtained based on the results of direct interviews with resource persons, namely the Branch Head of TIKI Salatiga. This research is descriptive qualitative using the Ward and Peppard method which includes SWOT analysis, Value Chain, PEST Analysis, and mapping of applications using the Mc Farlan Strategic Grid and analysis to provide Information Systems Recommendations. The final result of the research conducted is in the form of an Application Portfolio recommendation. Some of the proposed applications are TIKI Monitoring, Tiki Navigator, Tiki Order, TIKI Pay, and TIKI Mobile, whose systems are integrated with each other and presumably can be used sustainably in the next few years.
\end{abstract}

Keywords: Information System Strategic Planning, Ward and Peppard, SWOT, PEST, Value Chain, Application Portfolio.

\section{PENDAHULUAN}

Perkembangan teknologi pada era sekarang ini memiliki berkontribusi besar bagi sebuah organisasi maupun instansi dalam menjalankan proses bisnisnya, jadi antara bisnis dan teknologi informasi maupun sistem informasi harus berjalan dengan berkesinambungan, manfaat dari penerapan teknologi informasi atau sistem informasi bagi sebuah organisasi yaitu dapat digunakan sebagai media promosi, pencatatan, pelaporan maka dari beberapa contoh pekerjaan tersebut akan menjadi lebih efisien dan tujuan organisasi dapat tercapai, selain beberapa hal tersebut penggunaan TI/SI juga mampu menjaga informasi dan data-data penting yang berguna bagi kelangsungan bisnis, serta dapat menjadi keunggulan kompetitif dalam bersaing pada lingkup bisnis yang sejenis, berdasarkan beberapa

This work is licensed under a Creative Commons Attribution 4.0 International License. 
hal tersebut jelas penerapan TI/SI sangat penting agar tercipta efektivitas kinerja bagi organisasi maupun instansi. Maka dari itu diperlukan suatu perencanaan strategis sistem informasi untuk diimplementasikan pada lingkungan pendidikan yang dapat berjalan sesuai dengan visi, misi, dan proses bisnis agar tercapainya tujuan dari perusahaan [1].

TIKI merupakan salah satu perusahaan yang bergerak di bidang jasa ekspedisi yang ada di Kota Salatiga yang melayani pengiriman surat maupun barang, di era ini banyak bermunculan perusahaan ekspedisi baru yang kemunculannya meningkatkan persaingan di bidang jasa ekspedisi, serta ditambah dengan penawaran-penawaran menarik yang diberikan, maka dari itu dilakukannya penelitian ini adalah untuk mengetahui lebih jelas mengenai apa saja resiko-resiko yang timbul dengan munculnya perusahaan ekspedisi baru, tentunya seperti TIKI Salatiga harus mampu bersaing dan mempertahankan proses bisnis perusahaan, dipilihnya perencanaan strategis SI/TI ini diharapkan mampu menambah kekuatan bisnis dari TIKI Salatiga serta mampu meningkatkan pelayanan kepada konsumen.

Dipilihnya TIKI Salatiga sebagai lokasi studi kasus dalam penelitian ini yaitu dikarenakan belum adanya penelitian mengenai perencanaan strategis pada perusahaan ini, kemudian juga masih sedikitnya penelitian perencanaan strategis pada perusahaan yang bergerak dibidang sejenis. Nantinya penelitian ini akan membahas seputar ruang lingkup kerja dari TIKI Salatiga yaitu visi \& misi perusahaan proses bisnis yang dikerjakan, selanjutnya resiko-resiko bisnis yang dialami TIKI Salatiga, SI/TI yang telah diterapkan apa saja serta fungsi dari masing-masing sistem yang telah diimplementasikan, yang nantinya berdasarkan data-data tersebut akan dilakukan beberapa analisis dengan beberapa metode yang ada di dalam metodologi yang digunakan oleh peneliti.

Hasil penelitian ini akan menghasilkan portofolio aplikasi mendatang yang sekiranya dapat menunjang proses bisnis yang sudah ada, sehingga di era revolusi industri 4.0 TIKI Salatiga tetap mampu bersaing dengan tim ekspedisi baru, mampu memperoleh konsumen yang lebih banyak, meningkatkan efisiensi kinerja tim ekspedisi, serta mampu menjaga kepuasan konsumen, kemudian membantu pelacakan kiriman supaya paket ataupun surat sesuai dengan alamat yang dituju dengan tepat.

Perencanaan strategis pada TIKI Salatiga dilakukan dengan metode Ward and Peppard diharapkan nantinya menghasilkan portofolio sistem yang sejalan dengan proses bisnis, sehingga hasilnya sistem yang telah digunakan benar-benar bermanfaat bagi kemajuan perusahaan maupun organisasi terutama TIKI Salatiga. Pada penelitian sebelumnya mengungkapkan bahwa inti dari metodologi Ward and Peppard yaitu untuk memperoleh strategi yang tidak hanya terfokus 
terhadap SI/TI yang dimiliki perusahaan saja tetapi juga terkait dengan proses bisnis sampai portofolio yang dapat diimplementasikan oleh perusahaan [2]. Fungsi lain dari perencanaan strategis SI/TI dipakai untuk menyelaraskan antara keperluan strategi bisnis dan strategi SI/TI untuk mendapatkan nilai tambah bagi suatu organisasi dari segi keunggulan kompetitif [3].

Batasan penelitian ini adalah masa pandemi Covid-19 sehingga untuk melakukan wawancara langsung dituntut untuk wajib mengikuti aturan pemerintah mengenai protokol kesehatan. Penelitian ini dilakukan pada salah satu perusahaan ekspedisi di Kota Salatiga yaitu Citra Van Titipan Kilat (TIKI). Pada penelitian ini metodologi yang digunakan adalah Ward and Peppard yang didukung dengan metode analisis SWOT, PEST, Five Forces Model, kemudian Value Chain dan McFarlan Strategic Grid, selanjutnya untuk metode pengumpulan data yang digunakan adalah metode kualitatif deskriptif yang bersifat memberikan gambaran serta menjelaskan kondisi bisnis di dalam TIKI Salatiga [4].

Dengan demikian harapan setelah dilakukannya Perencanaan Strategis SI/TI pada TIKI Salatiga menggunakan metode Ward and Peppard ini mampu membantu meningkatkan keunggulan kompetitif bagi perusahaan serta dapat memaksimalkan penerapan SI/TI yang telah ada.

\section{METODE PENELITIAN}

\subsection{Framework Ward and Peppard}

Metodologi penelitian merupakan kerangka kerja yang digunakan dalam rangka mendapatkan serta mengumpulkan informasi maupun data serta selanjutnya melakukan investigasi pada data yang telah diperoleh yang nantinya memberikan gambaran sebuah rancangan penelitian yang mencakup beberapa poin penting yaitu: prosedur serta langkah-langkah yang harus dilakukan, waktu penelitian, sumber data, dan menggunakan cara seperti apa data tersebut dapat diperoleh yang tahap selanjutnya diolah dan dianalisis. Pada penelitian ini metodologi penelitian yang digunakan adalah metode Ward and Peppard yang di dalamnya terdapat teknik analisis yang diimplementasikan yaitu: SWOT, VALUE CHAIN, dan analisis PEST untuk menganalisa seperti apa lingkungan bisnis internal maupun eksternal beserta dengan resiko-resikonya, selanjutnya Mc Farlan Strategic Grid untuk memetakan portfolio aplikasi untuk mengembangkan lingkungan bisnis, sehingga penggunaan SI/TI dapat maskimal selaras dengan proses bisnis yang berlangsung [4]. 


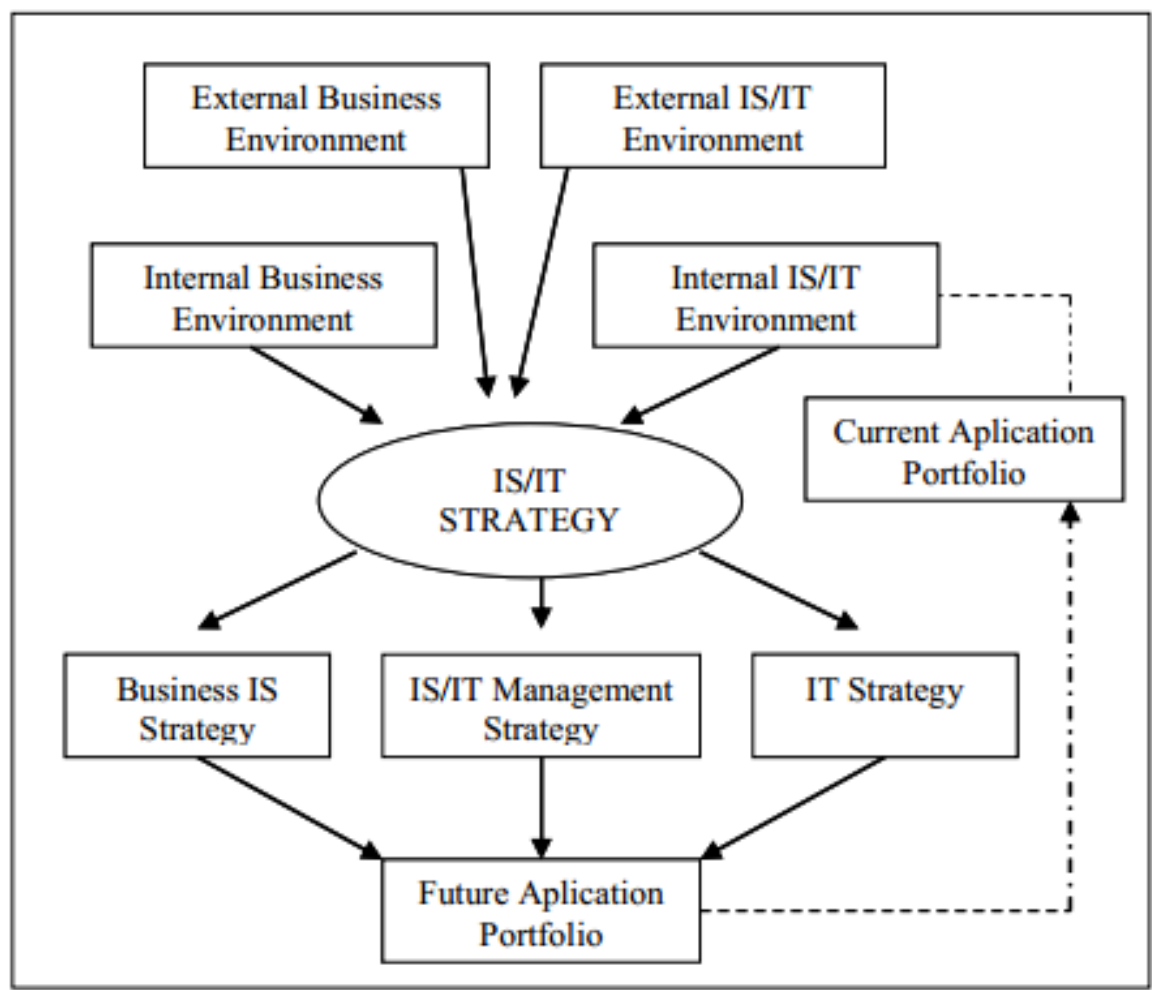

Gambar 1. Model Perencanaan Strategis SI/TI (Ward and Peppard 2002).

Dalam model ini terdapat tahapan masukan dan tahapan untuk keluaran. Berikut merupakan tahapan masukannya yaitu:

1. Analisis Lingkungan Bisnis Internal. Mengidentifikasi seperti apa dan sejauh apa proses bisnis dari TIKI Salatiga untuk mencapai tujuan dari organisasi serta menganalisa apa yang dapat diperbaiki atau dikembangkan kembali untuk meningkatkan keunggulan kompetitif.

2. Analisis Lingkungan Bisnis Eksternal. Mengidentifikasi perihal yang terjadi di luar perusahaan. Identifikasi lingkungan eksternal ini menggunakan metode PEST (Politik, Sosial, Ekonomi, Teknologi).

3. Analisis Lingkungan Internal SI/TI. Mengidentifikasi tentang keadaan SI/TI yang ada di TIKI Salatiga dengan melihat apakah sudah diimplementasikan dengan baik selaras dengan proses bisnis yang ada, kemudian ketersediaan SDM dalam kecakapan menggunakan SI/TI di perusahaan. 
4. Analisis Lingkungan Eksternal SI/TI. Mengidentifikasi trend penggunaan teknologi saat ini dari segi pelanggan maupun kompetitor.

Selanjutnya untuk tahapan keluarannya mencakup tentang Strategi SI Bisnis, Strategi TI, serta Strategi Manajemen SI/TI, berikut merupakan tahapan keluaran yang isinya yaitu:

1. Strategi SI Bisnis, mencakup bagaimana setiap bagian dari perusahaan dapat memanfaatkan SI/TI untuk mencapai tujuan bisnis dari TIKI Salatiga.

2. Strategi TI, meliputi strategi pengelolaan teknologi dan sumber daya manusia dari TIKI Salatiga.

3. Strategi Manajemen SI/TI, yang mencakup kebijakan SI/TI yang dibutuhkan pada TIKI Salatiga agar penggunaannya dapat maksimal.

Dari tahapan masukan dan keluaran tersebut nantinya akan menghasilkan pemetaan aplikasi dengan menggunakan Mc Farlan Strategic Grid di TIKI Salatiga yang di dalam penyusunannya berdasarkan kategori High Potential, Strategic, Support, dan Key Operational. Hasil akhirnya nanti yaitu sebuah portfolio aplikasi yang sedang digunakan dan yang akan direncanakan pada masa yang akan datang bagi perusahaan serta mengintegrasikan setiap unit dari perusahaan dan menyelaraskan perkembangan teknologi dengan perkembangan bisnis perusahaan itu sendiri [5].

\subsection{Teknik Pengumpulan Data}

Teknik pengumpulan data yang digunakan yaitu dengan metode kualitatif, metode kualitatif merupakan metode yang fokus pada pengamatan yang mendalam, hasil dari penggunaan metode kualitatif ini adalah berupa sebuah kajian atas suatu fenomena yang lebih komprehensif. Pengumpulan data dilakukan dengan melakukan wawancara langsung dengan narasumber terkait untuk mendapatkan informasi detail yang diperlukan dari TIKI Salatiga [6].

\section{HASIL DAN PEMBAHASAN}

\subsection{Profil Lengkap Organisasi atau Perusahaan}

PT. Citra Van Titipan Kilat (TIKI) merupakan perusahaan pengiriman barang yang didirikan oleh Alm. Bpk Soeprapto Soeparno dan Ibu Nuraini Soprapto pada 1 September 1970. Pada kota salatiga TIKI memiliki 25 gerai, salah satunya terletak di Jl. KH Wahid Hasyim No. 16 E, Sidorejo Lor, Salatiga. Jaringan TIKI 
Vol. 3, No. 1, March 2021

p-ISSN: 2656-5935 http://journal-isi.org/index.php/isi e-ISSN: 2656-4882

saat ini memiliki 65 kantor cabang di kota-kota besar, 430+ sub-cabang, 3000+ gerai, 12000+ karyawan dan sekitar 4000 armada. Saat ini TIKI telah melayani 98\% Kode pos, 88\% Kabupaten/kota, 67\% Kelurahan atau Desa dan terus memperluas jaringannya.

Pada tahun ini PT. Citra Van Titipan Kilat (TIKI) mendapat penghargaan 'Better Brand Awards 2019' sebagai perusahaan yang konsisten berinovasi memberikan layanan yang lebih baik kepada konsumen, sebelumnya TIKI juga memperoleh penghargaan $2^{\text {nd }}$ Millennial Choice untuk kategori Courier Services di ajang Indonesia Millennial's Top Brand Award 2019.

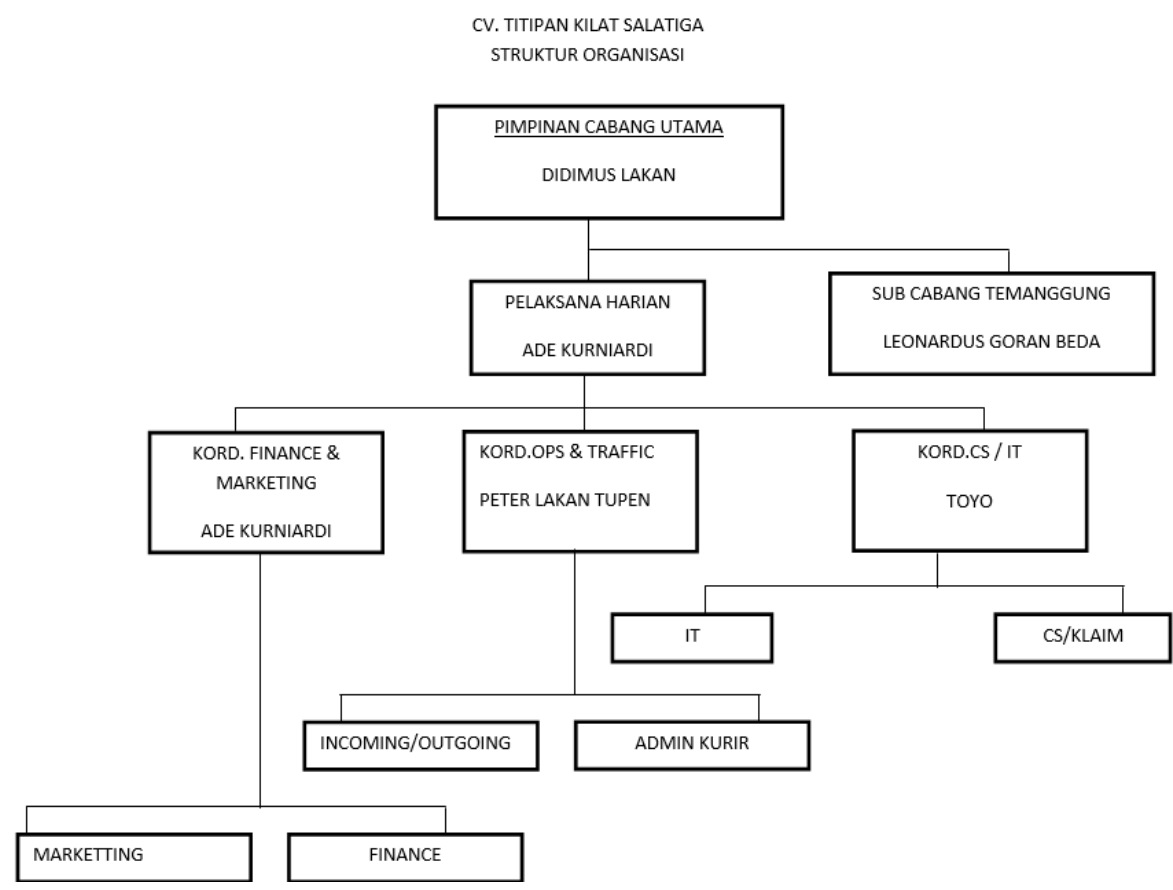

Gambar 1. Struktur Organisasi Citra Van Titipan Kilat

\subsection{Identifikasi Visi-Misi, Tujuan, dan Sasaran Organisasi/Perusahaan}

A. Visi

Menjadikan TIKI sebagai salah satu perusahaan yang terbaik dalam jasa pengiriman dan logistik dengan melayani kebutuhan dan kepentingan pelanggan secara optimal sehingga dikenal di indonesia dan internasional

B. Misi

Bekerja giat secara profesional,jujur,bertanggung jawab dengan penuh keyakinan dan dedikasi tinggi untuk selalu menjadi yang terbaik 
C. Tujuan

Menjadi perusahaan yang terbaik dalam pengiriman ekspedisi

D. Sasaran Produk

Tiki menargetkan untuk melayani pengiriman barang,penerimaan barang, dokumen,serta pengiriman dari luar negeri ke indonesia

Untuk mengidentifikasi visi-misi,tujuan dan sasaran organisasi/perusahaan kami menggunakan analisis SMART. Analisis SMART adalah konsep untuk merumuskan tujuan secara efektif, Konsep ini terdiri dari 5 langkah penetapan yaitu, Specific, Measurable, Achievable, Realistic, Timely.

1. Specific

Salah satu poin penting dalam analisis SMART adalah tujuan harus dirumuskan secara jelas dan mudah dipahami oleh semua anggota. Menurut kami, visi yang dimiliki TIKI sudah berjalan dengan baik terbukti dari TIKI pernah memenangkan penghargaan $2^{\text {nd }}$ Millennial Choice untuk kategori Courier Services di ajang Indonesia Millennial's Top Brand Award 2019. Artinya, setiap karyawan memahami mengenai visi yang dianut oleh perusahaan sehingga visi tersebut dapat tercapai

2. Measureble

Measureble merupakan sebuah indikator atau sebuah ukuran untuk mencapai target perusahaan. Perusahaan PT.Titipan Kilat Salatiga menargetkan bahwa perusahaan tersebut akan dikenal seluruh dunia.

Untuk mencapai target tersebut perusahaan membuka gerai,cabang,dan sub cabang di kota kota besar.Saat ini TIKI telah melayani 98\% kode pos, 88\% kabupaten/kota, 67\% kelurahan atau desa dan terus memperluas jaringannya. Artinya TIKI secara konsisten terus meningkatkan jasanya dalam pengiriman barang

3. Achievable

Pada tahun ini PT. Citra Van Titipan Kilat (TIKI) mendapat penghargaan 'Better Brand Awards 2019' sebagai perusahaan yang konsisten berinovasi memberikan layanan yang lebih baik kepada konsumen, sebelumnya TIKI juga memperoleh penghargaan $2^{\text {nd }}$ Millennial Choice untuk kategori Courier Services di ajang Indonesia Millennial's Top Brand Award 2019.

Prestasi yang diraih membuktikan bahwa TIKI mampu mencapai visi dan misi yang sudah ditetapkan sebelumnya, yaitu menjadi perusahaan yang terbaik dalam jasa pengiriman dan logistik dengan melayani kebutuhan dan 
kepentingan pelanggan secara optimal sehingga dikenal di indonesia dan internasional serta bekerja dengan penuh tanggung jawab dan dedikasi tinggi

4. Realistic

Sejak perusahaan TIKI berdiri, mereka selalu konsisten dalam memberikan pelayanan terhadap pelanggan,terbukti dari beberapa aplikasi yang dipakai untuk menunjang pelayanan terhadap pelanggan. Aplikasi yang dipakai adalah: CASH AUTOMATION, SMART, DMS, TIKI SPRINTER. Dari aplikasi tersebut TIKI selalu berinovasi dalam memberikan pelayanan terhadap pelanggan dan sesuai dengan kemajuan bisnis online, dimana banyak pelanggan menggunakan hadphone untuk mendukung kegiatan.

5. Time able

Dalam visi misi dan tujuan Perusahaan TIKI tidak mencantumkan kapan semua target itu harus dicapai, sehingga dapat berdampak pada pertumbuhan perusahaan. Dengan tidak ada nya target yang jelas membuat kinerja pegawai tidak meningkat

\subsection{Analisis Lingkungan Internal dan Eksternal}

\subsubsection{Analisis SWOT}

Langkah pertama dalam perencanaan strategis sistem informasi di TIKI Salatiga yaitu analisis dari lingkungan bisnis internal dan bisnis eksternal sekaligus dengan menggunakan alat analisa SWOT (Strengths, Weakness, Opportunities, and Threats) [7]. Analisis SWOT digunakan untuk mengetahui kekuatan, kelemahan, peluang, dan ancaman perusahaan TIKI Salatiga baik yang berasal dari dalam maupun dari luar perusahaan yang terdiri dari:

\begin{tabular}{|c|l|l|}
\hline 1. & $\begin{array}{l}\text { Kekuatan } \\
\text { (Strength) }\end{array}$ & $\begin{array}{l}\text { Memiliki jaringan integrasi sistem yang luas di Indonesia } \\
\text { Adanya dukungan modal finansial dari pusat untuk } \\
\text { berinovasi }\end{array}$ \\
\hline 2. & $\begin{array}{l}\text { Kelemahan } \\
\text { (Weakness) }\end{array}$ & $\begin{array}{l}\text { SDM yang ada masih perlu dilatih dalam pemakaian IT } \\
\text { karena masih banyak aktivitas bersifat konvensional } \\
\text { Menambah jumlah pegawai divisi IT, dikarenakan masih } \\
\text { kurang } \\
\text { Sistem informasi masih hanya berbasis website }\end{array}$ \\
\hline 3. & $\begin{array}{l}\text { Peluang } \\
\text { (Opportunities) }\end{array}$ & $\begin{array}{l}\text { Perusahaan telah memanfaatkan bidang IT sebagai salah } \\
\text { satu ujung tombaknya serta belum banyak rival } \\
\text { perusahaan di Kota Salatiga yang juga memakai IT }\end{array}$ \\
\hline
\end{tabular}




\begin{tabular}{|l|l|l|}
\hline 4. & $\begin{array}{l}\text { Ancaman } \\
\text { (Threats) }\end{array}$ & $\begin{array}{l}\text { Perkembangan persaingan antar perusahaan bidang } \\
\text { ekspedisi yang mulai membangun sistem tata kelola IT } \\
\text { nya masing-masing }\end{array}$ \\
\hline
\end{tabular}

Gambar 1. Analisis SWOT TIKI

\subsubsection{Analisis Value Chain}

Alat analisis kedua untuk melihat aktivitas utama dan aktivitas pendukung dari TIKI yang digunakan yaitu Porter's Value Chain Analysis. Analisis Porter's Value Chain dilakukan untuk menggambarkan aktivitas proses bisnis utama dan proses bisnis pendukung dari perusahaan. Analisis ini juga bertujuan untuk mengidentifikasi dan mengelompokkan aktivitas-aktivitas yang terjadi di perusahaan ke dalam dua bagian besar yaitu aktivitas utama dan aktivitas pendukung [8]. Hasil analisis ini kemudian akan digunakan untuk mengidentifikasi kebutuhan sistem informasi di perusahaan.

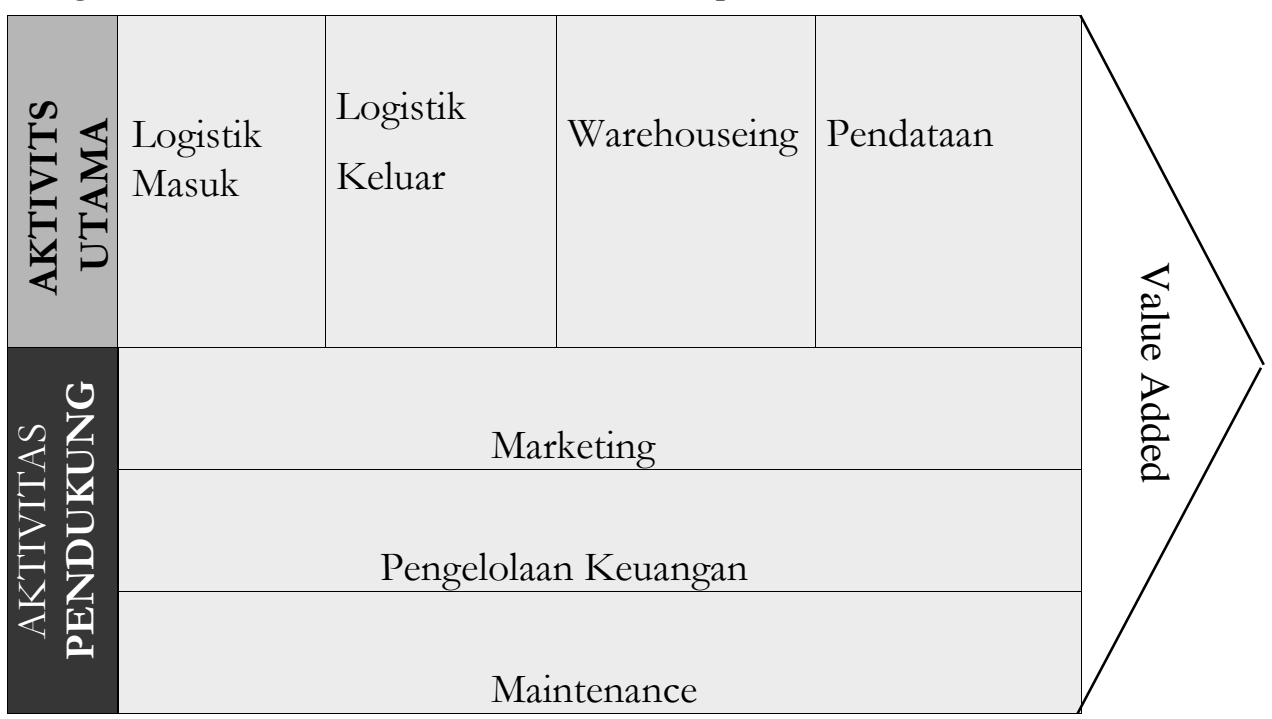

\section{Gambar 2. Porter's Value Chain Analysis TIKI}

Berdasarkan dari Gambar 2, maka dari analisis Value Chain tersebut diperoleh informasi sebagai berikut:

1. Aktivitas Utama

a. Logistik Masuk

- Merupakan aktivitas dimana pelanggan akan mengirimkan barang melalui ekspedisi Citra Van Titipan Kilat Salatiga. 
b. Logistik Keluar

- Yaitu pengiriman barang dari Citra Van Titipan Kilat Salatiga ke alamat para pelanggan.

c. Warehousing

- Sebelum barang dikirimkan ke pelanggan maka barang di simpan di gudang terlebih dahulu untuk dilakukan penyortiran.

d. Pendataan

- Merupakan aktivitas pencatatan secara sistem mengenai informasi dari sebuah barang yang akan dikirimkan.

2. Aktivitas Pendukung

a. Marketing

- Strategi dalam menawarkan jasa pengiriman dari Citra Van Titipan Kilat Salatiga.

b. Pengelolaan Keuangan

- Manajemen keuangan yang masuk maupun keluar untuk keperluan ekspedisi Citra Van Titipan Kilat Salatiga.

c. Maintenance

- Pengecekan berkala terhadap SI/TI yang dimiliki oleh perusahaan.

\subsection{Analisis Lingkungan SI/TI Internal dan Eksternal}

\subsubsection{Analisis Lingkungan SI/TI Internal}

Dalam melakukan identifikasi penerapan sistem informasi di TIKI Salatiga, maka dilakukan analisis lingkungan sistem informasi secara internal yang digunakan di perusahaan saat ini yang dilakukan terhadap segala sumber daya sistem informasi dan teknologi informasi yang tersedia. Sumber daya yang dimaksud adalah sistem informasi dalam bentuk aplikasi, teknologi informasi dalam bentuk perangkat keras, dan sumber daya manusia yaitu pengguna sistem informasi atau manajemen sistem informasi yang terdapat di perusahaan saat ini. Adapun daftar sistem informasi yang digunakan oleh perusahaan saat ini yaitu seperti pada Gambar 3. di bawah ini:

\begin{tabular}{|l|l|l|l|}
\hline No & Nama Aplikasi & User & Jenis Aplikasi \\
\hline 1 & Tiki Sprinter & Kurir & Mobile \\
\hline 2 & TIKI CS auto & Cs & Desktop \\
\hline 3 & DMS & Traffic & Desktop \\
\hline
\end{tabular}


Vol. 3, No. 1, March 2021

p-ISSN: 2656-5935 http://journal-isi.org/index.php/isi e-ISSN: 2656-4882

\begin{tabular}{|l|l|l|l|}
\hline 4 & Smart & Traffic & Desktop \\
\hline
\end{tabular}

Gambar 3. SI/TI Internal TIKI

\subsubsection{Analisis Lingkungan SI/TI Eksternal}

Pada era ini terbukti perkembangan teknologi sangar berkembang sangat cepat, kemudian banyak bermunculan banyak perusahaan ekspedisi baru yang mulai eksis namanya, semakin ketatnya persaingan dari segi bisnis maupun teknologi menuntut TIKI Salatiga untuk berinovasi sesuai perkembangan teknologi dan terbukti dengan SI/TI yang telah dimiliki Citra Van Titipan Kilat Salatiga tetap mampu bersaing dan menjaga performa dari pelayanannya.

\subsection{Matrik SWOT}

Berdasarkan hasil analisa SWOT TIKI Salatiga pada tabel sebelumnya, maka dapat dirumuskan rumusan guna perencanaan strategis sistem informasi di TIKI Salatiga sebagai berikut:

\begin{tabular}{|c|c|}
\hline S-O & S-T \\
\hline 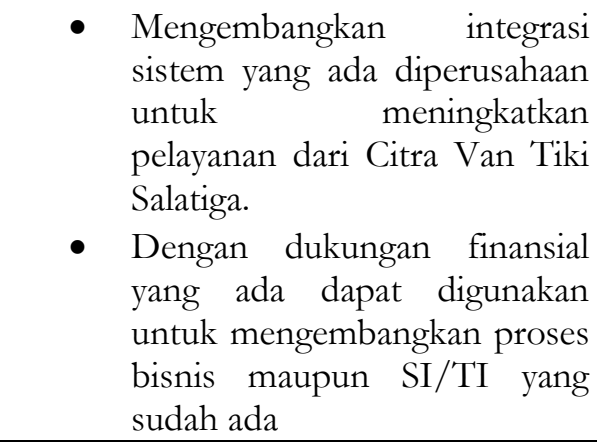 & 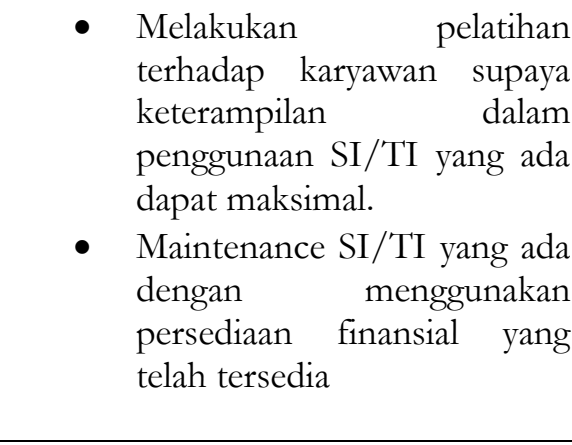 \\
\hline W-O & W-T \\
\hline $\begin{array}{l}\text { - Meningkatkan jumlah SDM } \\
\text { yang kompeten untuk } \\
\text { mengelola SI/TI yang telah } \\
\text { lama digunakan. }\end{array}$ & $\begin{array}{l}\text { - } \begin{array}{l}\text { Menjaga kualitas dari } \\
\text { pelayanan dari segi bisnis } \\
\text { maupun IT. }\end{array} \\
\text { - } \begin{array}{l}\text { Meningkatkan } \\
\text { pelayanan }\end{array}\end{array}$ \\
\hline
\end{tabular}

\section{Gambar 4. Matrik SWOT TIKI}

\subsection{Usulan Sistem Informasi}

Berdasarkan hasil analisis yang diperoleh dari beberapa tahapan sebelumnya yaitu analisis bisnis SI/TI internal dari TIKI Salatiga , maka kemudian akan menjadi 
Vol. 3, No. 1, March 2021

p-ISSN: 2656-5935 http://journal-isi.org/index.php/isi e-ISSN: 2656-4882

masukan pada tahapan usulan strategi solusi sistem informasi untuk perusahaan TIKI Salatiga [9]. Adapun usulan strategi solusi sistem informasi untuk perusahaan TIKI Salatiga adalah seperti pada Gambar 5. berikut :

\begin{tabular}{|l|l|l|l|}
\hline No & $\begin{array}{l}\text { Nama Usulan Sistem } \\
\text { Informasi }\end{array}$ & User & Jenis Aplikasi \\
\hline 1 & Tiki Monitoring (dashboard ) & $\begin{array}{l}\text { Kepala } \\
\text { Cabang \& CS }\end{array}$ & Web \\
\hline 2 & $\begin{array}{l}\text { Tiki Mobile ( app tiki khusus } \\
\text { android ) }\end{array}$ & User & Mobile \\
\hline 3 & Tiki Pay (E-money tiki) & User & Mobile \\
\hline 4 & $\begin{array}{l}\text { Tiki Navigator ( AI rute, geo } \\
\text { target penghitung estimasi) } \\
\text { untuk kurir }\end{array}$ & Kurir & Web \\
\hline 5 & $\begin{array}{l}\text { Tiki Order (layanan khusus } \\
\text { pelanggan dapat menyuruh } \\
\text { kurir ambil barang } \\
\text { dirumah/tempat lain) }\end{array}$ & User & Mobile \\
\hline
\end{tabular}

Gambar 5. Usulan Sistem Informasi TIKI

\subsection{Portofolio Aplikasi}

Kemudian berdasarkan strategi solusi sistem informasi TIKI Salatiga dalam bentuk aplikasi-aplikasi seperti pada Gambar $\mathbf{5}$ tersebut akan dipetakan sesuai fungsinya masing-masing menggunakan matriks Mc Farlan Strategic Grid guna mengetahui prioritas aplikasi yang akan diterapkan di perusahaan di masa mendatang [10]. Pemetaan Mc Farlan Strategic Grid bertujuan untuk menganalisis suatu sistem informasi atau aplikasi di perusahaan berdasarkan kondisi saat ini maupun kondisi yang direncanakan di masa mendatang serta aplikasi-aplikasi yang dianggap berpotensi dalam menunjang bisnis operasional perusahaan. Pemetaan tersebut dibagi atas kategori yang didefinisikan sebagai berikut:

1) Kuadran 1 merupakan kuadran Support.

2) Kuadran 2 merupakan kuadran Key Operational.

3) Kuadran 3 merupakan kuadran High Potential.

4) Kuadran 4 merupakan kuadran Strategic.

Adapun matriks Mc Farlan Strategic Grid yang digunakan untuk pemetaan aplikasi mendatang di TIKI Salatiga dapat dilihat pada tabel Gambar 6 di bawah ini. 


\begin{tabular}{|c|c|}
\hline Strategic & High Potensial \\
\hline$\bullet \quad$ DMS & $\bullet$ SI Tiki navigator \\
$\bullet \quad$ TIKI CS auto & Key Operational \\
\hline Support & $\bullet$ Tiki Pay \\
$\bullet \quad$ SI Tiki order & $\bullet$ SI Tiki monitoring \\
$\bullet$ Smart & $\bullet$ Tiki mobile \\
\hline
\end{tabular}

Gambar 6. Portofolio Aplikasi Mendatang Mc Farlan

\subsection{Analisis Kesenjangan Aplikasi}

Berdasarkan prioritas yang telah dipetakan sebelumnya ke dalam Mc Farlan Strategic Grid, maka selanjutnya akan dilakukan analisis kesenjangan aplikasi yang harus ada untuk memenuhi kebutuhan di TIKI Salatiga [11]. Analisis ini dilakukan untuk menentukan aplikasi apa saja yang memerlukan tindakan upgrade, delete, dan direncanakan (planing) supaya SI/TI tetap selaras dengan bisnis yang dijalankan oleh perusahaan seperti pada tabel Gambar 7 di bawah ini.

\begin{tabular}{|l|l|l|l|l|}
\hline No & Nama aplikasi & Upgrade & Delete & Planing \\
\hline 1 & Tiki Pay & & & $\checkmark$ \\
\hline 2 & SI Tiki Monitoring & & & $\checkmark$ \\
\hline 3 & Tiki Mobile & & & $\checkmark$ \\
\hline 4 & SI Tiki Order & & & $\checkmark$ \\
\hline 5 & SMART & $\checkmark$ & & \\
\hline 6 & SI Tiki Navigator & & & $\checkmark$ \\
\hline 7 & DMS & $\checkmark$ & & \\
\hline 8 & TIKI CS auto & & $\checkmark$ & \\
\hline & & & & \\
\hline
\end{tabular}

Gambar 7. Analisis Kesenjangan Aplikasi TIKI

\section{KESIMPULAN}

Berdasarkan hasil penelitian yang telah dilakukan pada saat ini TIKI Salatiga telah mengimplementasikan sistem informasi dan teknologi informasi dengan baik hanya saja belum optimal sepenuhnya. Berdasarkan analisa dengan menggunakan 
metode Ward and Peppard dengan analisis SWOT, Analisis Value Chain, serta Mc Farlan Strategic Grid yang didukung pula dengan analisis lingkungan internal dan eksternal perusahaan, maka diperolehlah hasil sebuah portofolio aplikasi usulan berjumlah 4 sistem informasi yaitu TIKI Monitoring, TIKI Navigator, TIKI Pay, TIKI Order, dan TIKI Mobile.

Diharapkan dengan adanya perencanaan strategis sistem informasi ini dapat diimplementasikan serta dikembangkan oleh TIKI Salatiga untuk terus menjaga kualitas pelayanan, mengefisienkan kinerja dari perusahaan dan menghasilkan keunggulan kompetitif bagi perusahaan.

\section{DAFTAR PUSTAKA}

[1] S. D. Deomedes and A. Kurniawan, "Pada Perusahaan Farmasi Yang Terdaftar," vol. 15, no. 2, pp. 100-115, 2018.

[2] Y. Firmansyah and D. Purwaningtias, "Analisa Metodologi Ward \& Peppard Dalam Penentuan Perencanaan Strategis SI/TI," Cybernetics, vol. 1, no. 02, p. 70, 2017, doi: 10.29406/cbn.v1i02.725.

[3] Ari Wedhasmara, "LANGKAH-LANGKAH PERENCANAAN STRATEGIS SISTEM INFORMASI DENGAN MENGGUNAKAN METODE WARD AND PEPPARD | Wedhasmara | Jurnal Sistem Informasi," Jsi, vol. VOL. 1, NO, no. 1, pp. 14-22, 2017, [Online]. Available: https://ejournal.unsri.ac.id/index.php/jsi/article/view/704.

[4] A. F. Wijaya and V. D. R. Damara, "Perencanaan Strategis Si/Ti Pada Document Management Menggunakan Ward and Peppard (Studi Kasus: Pt. Visionet Data International)," J. Bina Komput., vol. 2, no. 1, pp. 33-43, 2020, doi: 10.33557/binakomputer.v2i1.796.

[5] A. Wiyono and A. F. Wijaya, "PERENCANAAN STRATEGIS SISTEM INFORMASI DI PT TELEKOMUNIKASI INDONESIA, Tbk WITEL SEMARANG MENGGUNAKAN WARD AND PEPPARD," J. Bina Komput., vol. 2, no. 1, pp. 23-32, 2020, doi: 10.33557/binakomputer.v2i1.797.

[6] Yoni Ardianto, "Memahami Metode Penelitian Kulitatif," 06 Maret 2019, 2020.

https://www.djkn.kemenkeu.go.id/artikel/baca/12773/Memahami-

Metode-Penelitian-Kualitatif.html\#: :text=Metode kualitatif merupakan metode yang,suatu fenomena yang lebih komprehensif. (accessed Jan. 05, 2019).

[7] M. Ary and R. Sanjaya, "Strategi Perencanaan Dan Pengembangan Program Studi Menggunakan Analisis Swot (Studi Kasus Program Studi 
Sistem Informasi Ars University)," J. Tekno Insentif, vol. 14, no. 1, pp. 1-8, 2020, doi: $10.36787 /$ jti.v14i1.198.

[8] F. D. Oes, "Perencanaan Strategis Sistem Informasi Menggunakan Pendekatan Five Forces dan Value Chain Activity pada Pertambakan Budidaya Udang di PT. Asindo Setia Tamal," no. September, 2015.

[9] P. Strategis et al., "Metode Ward and Peppard ( Studi Kasus: Dinas Kependudukan Dan Pencatatan Sipil Kota Tomohon )," pp. 604-610.

[10] Wulandana and Anharudin, "Perencanaan Strategis Sistem Informasi Menggunakan Model Be Vissta Planning (BVP) Pada Perusahaan Pencelupan Kain Tekstil ( Studi Kasus: PT . Cipta Artha Graha Mulia)," Prosisko, vol. 3, no. 1, pp. 1-5, 2016.

[11] Anharudin, "Perencanaan Strategis Sistem Informasi Untuk Meningkatkan Pelayanan Menggunakan Metode Ward And Peppard ( Studi Kasus: Pt Pos Indonesia Cilegon - Banten)," J. PROSISKO, vol. 2, no. 2, pp. 1-4, 2015. 